
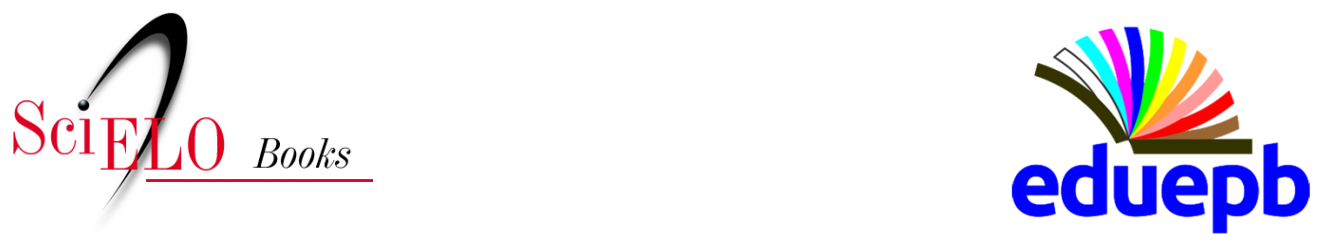

\title{
O Estado da Arte sobre Migração Forçada no Brasil, entre 2007 e 2017
}

\author{
Andrea Pacheco Pacífico \\ Andrezza Teles Pinheiro \\ Júlia Patrícia Ferreira de Vasconcelos Granja \\ Adolfino Varela
}

\section{SciELO Books / SciELO Livros / SciELO Libros}

PACÍFICO, A. P., PINHEIRO, A. T., GRANJA, J. P. F. V., and VARELA, A. O Estado da Arte sobre Migração Forçada no Brasil, entre 2007 e 2017. In: $O$ Estado da Arte sobre Refugiados, Deslocados Internos, Deslocados Ambientais e Apátridas no Brasil: atualização do Diretório Nacional do ACNUR de teses, dissertações, trabalhos de conclusão de curso de graduação em João Pessoa (Paraíba) e artigos (2007 a 2017) [online]. Campina Grande: EDUEPB, 2020. pp. 47-62. ISBN:978-65-87171-12-8. https://doi.org/10.7476/9786587171128.0005.

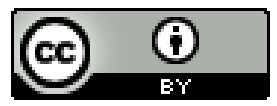

All the contents of this work, except where otherwise noted, is licensed under a Creative Commons Attribution 4.0 International license.

Todo o conteúdo deste trabalho, exceto quando houver ressalva, é publicado sob a licença Creative Commons Atribição 4.0.

Todo el contenido de esta obra, excepto donde se indique lo contrario, está bajo licencia de la licencia Creative Commons Reconocimento 4.0. 


\section{O Estado da Arte sobre Migração Forçada no Brasil, entre 2007 e 2017}

Com relação às teses e dissertações, a partir dos dados coletados, foi possível identificar que foram publicadas, no Brasil, entre 2007 e 2017, a quantidade de 13 teses de doutorado e 63 dissertações de mestrado, cujos gêneros dos autores (76) são 57 mulheres e 19 homens.

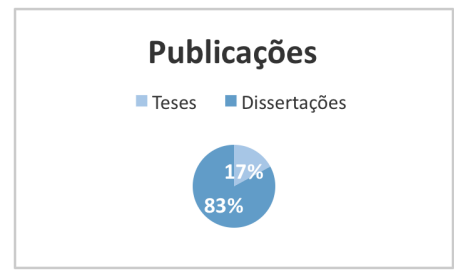

Figura 1 - Publicações

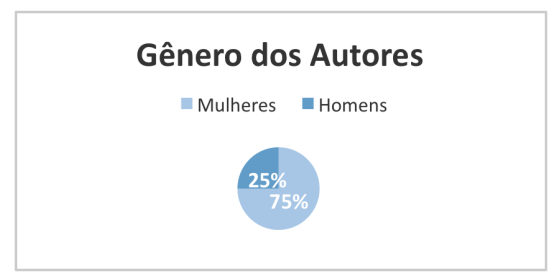

Figura 2-Gêneros dos autores

Fonte: Pesquisa de campo dos autores. Fonte: Pesquisa de campo dos autores.

Quanto à natureza das Instituições de Ensino Superior (IES), onde estas pesquisas foram desenvolvidas, 45 delas são públicas, 16 privadas e 15 privadas-religiosas. Quanto aos Estados das IES, houve uma (1) publicação em cada um dos seguintes estados: Alagoas, Bahia, Ceará, Espírito Santo, Mato Grosso do Sul, Paraíba e Pernambuco; duas (2) publicações no Amazonas, Distrito Federal e Pará; três (3) em Minas Gerais; 
quatro (4) no Paraná; sete (7) em Santa Catarina; dez (10) no Rio Grande do Sul; doze (12) no Rio de Janeiro e vinte e sete (27) em São Paulo.

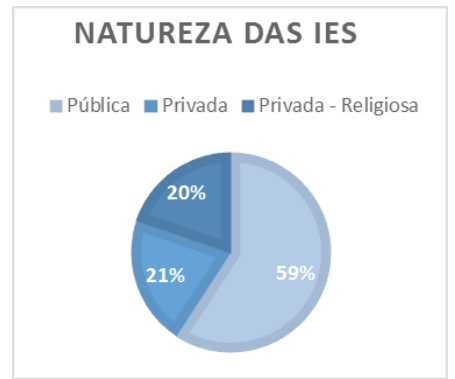

Figura 3 - Natureza das IES

Fonte: Pesquisa de campo dos autores

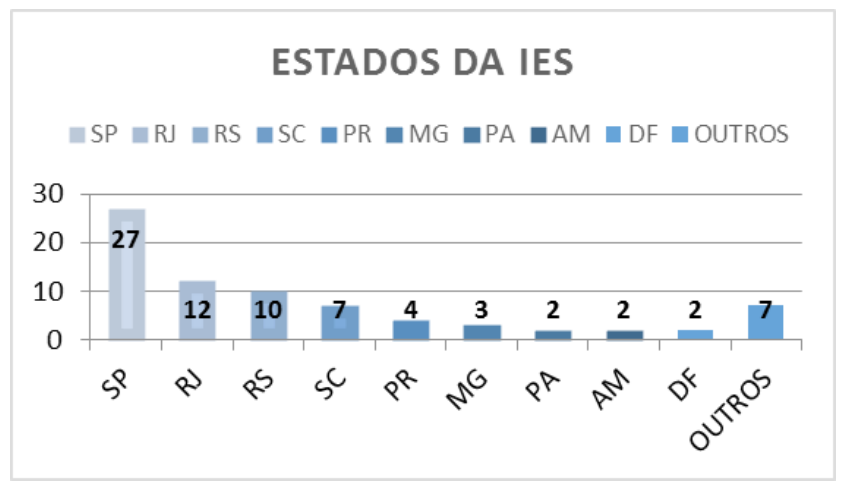

Figura 4-Estado das IES

Fonte: Pesquisa de campo dos autores.

Com relação à área de conhecimento dos programas de pós-graduação das teses e das dissertações publicadas, foram realizadas pesquisas nas seguintes áreas, encontrando-se a quantidade em parênteses: Antropologia (4), Ciência Política e Relações Internacionais (3), Ciências (3), Demografia (5), Direito (40), Letras (5), Psicologia (3), Sociologia (7) e uma 
(1) em Comunicação, Economia, Educação, História, Saúde e Serviço Social.

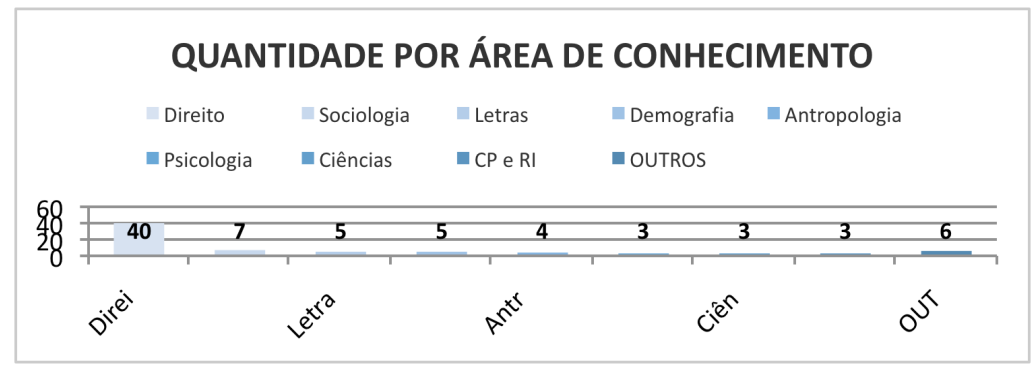

Figura 5 - Quantidade por área de conhecimento

Fonte: Pesquisa de campo dos autores.

Em seguida, foi identificada a defesa/apresentação de 43 trabalhos de conclusão de curso (TCC) de graduação em Instituições de Ensino Superior (IES) situadas em João Pessoa, entre 2007 e 2017, sendo que, quanto ao gênero dos autores, foram 29 mulheres e 14 homens. Quanto à natureza das Instituições de Ensino Superior (IES) em que estes TCC foram desenvolvidos, 37 delas são públicas (sendo 21 estaduais e 16 federais) e 6 privadas.

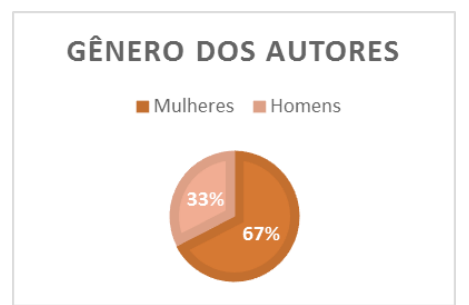

Figura 6 - Gênero dos autores Fonte: Pesquisa de campo dos autores

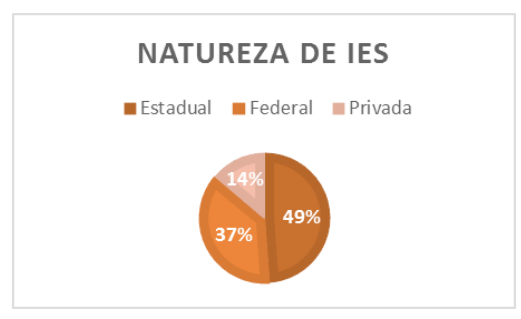

Figura 7 - Natureza de IES Fonte: Pesquisa de campo dos autores 
Quanto ao ano de publicação dos TCC, entre 2007 e 2017, foram dezesseis (16) em 2016, nove (9) em 2014, cinco (5) em 2017, quatro (4) em 2013, dois (2) em 2015 e dois (2) em 2011 e apenas um (1) em cada um dos anos seguintes: 2012, 2010, 2009, 2008 e 2007.

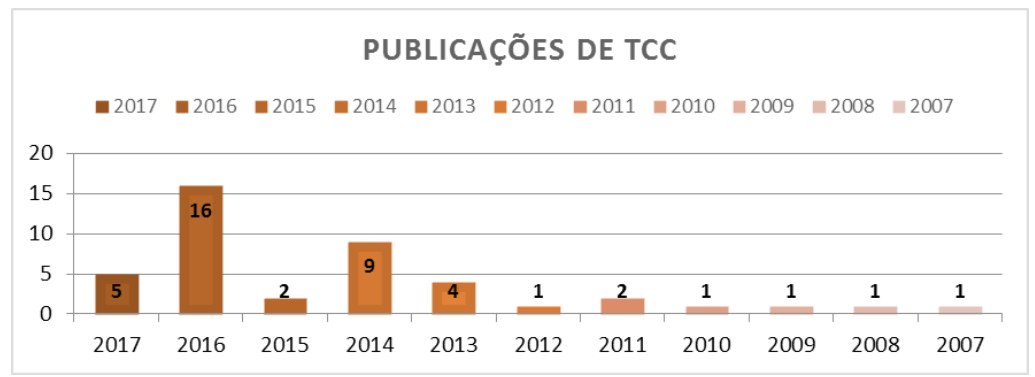

Figura 8 - Publicações de TCC

Fonte: Pesquisa de campo dos autores.

Com relação à área de conhecimento dos cursos de graduação dos TCC publicados, foram realizadas pesquisas nas seguintes áreas, encontrando-se a quantidade em parênteses: Relações Internacionais (25), Direito (16), Geociência (1) e Ciências Econômicas (1).

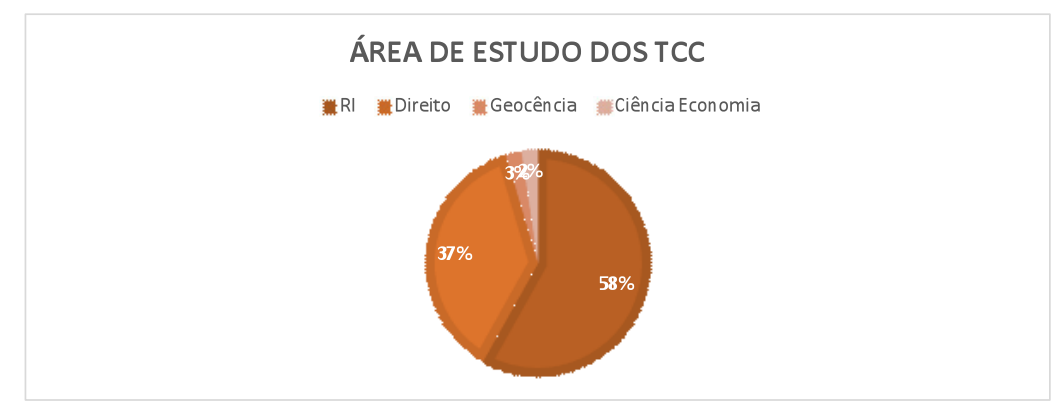

Figura 9-Área de estudo dos TCC

Fonte: Pesquisa de campo dos autores. 
Foram, ainda, publicados, no Brasil, entre 2007 e 2017, 340 artigos em periódicos: A1 (62 artigos), A2 (93 artigos) e B1 (185 artigos), conforme classificação do Qualis-Capes (2016), cujos gêneros dos autores e coautores (522) são 304 mulheres e 218 homens.

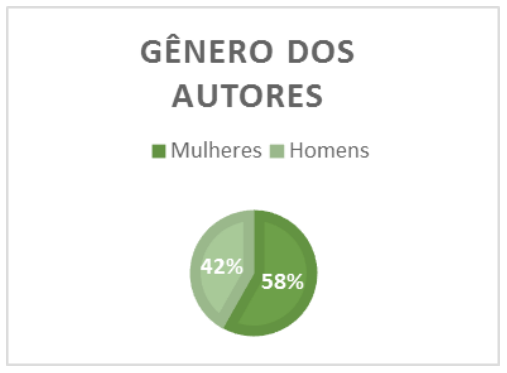

Figura 10 - Gênero dos autores

Fonte: Pesquisa de campo dos autores

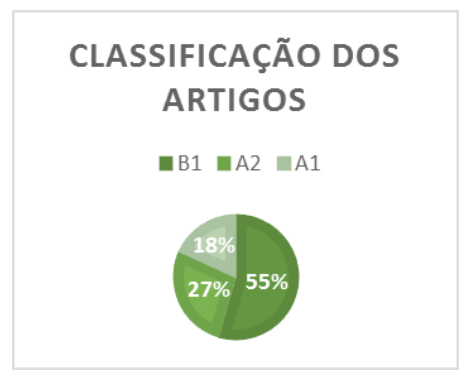

Figura 11 - Classificação dos artigo Fonte: Pesquisa de campo dos autores

Com relação à área de conhecimento dos periódicos, conforme classificação do Qualis-Capes, foram pesquisados 185 artigos publicados em periódicos $\mathrm{B} 1$, sendo 53 na área de Ciência Política e Relações Internacionais, 50 em Sociologia, 45 em Direito, 11 em História, 11 em Antropologia, 8 em Psicologia e 7 em Serviço Social.

Saliente-se, quanto às áreas de classificação dos artigos publicados, que foram contabilizados 262 autores e coautores (163 mulheres e 99 homens) destes artigos em periódicos B1, sendo 81 (49 mulheres e 31 homens) na área de Ciência Política e Relações Internacionais, 71 (45 mulheres e 26 homens) na área de Sociologia, 61 (38 mulheres e 23 homens) na área de Direito, 14 (10 mulheres e 4 homens) na área de Antropologia, 12 (5 mulheres e 7 homens) na área de História, 12 (7 mulheres e 5 homens) na área de Psicologia e 11 na área de Serviço Social (9 mulheres e 2 homens). 


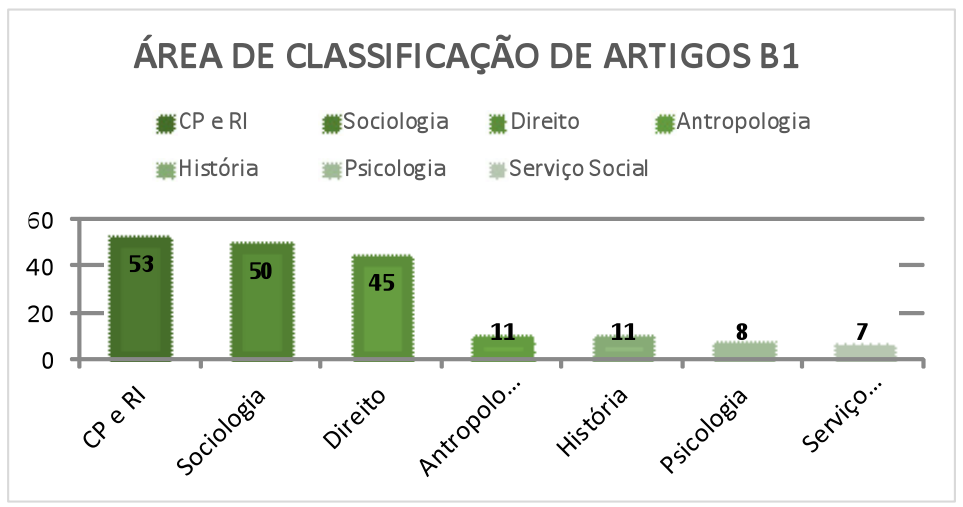

Figura 12 - Área de classificação de artigos B1

Fonte: Pesquisa de campo dos autores.

Também foram pesquisados 93 artigos publicados em periódicos A2, sendo 28 na área de classificação de Ciência Política e Relações Internacionais, 21 em Antropologia, 18 em História, 16 em Sociologia, 10 em Direito, 8 em Serviço Social e 2 em Psicologia.

Saliente-se que foram contabilizados 153 autores e coautores (65 mulheres e 88 homens) destes artigos publicados em periódicos A2, sendo 44 (21 mulheres e 23 homens) na área de Ciência Política e Relações Internacionais, 41 (26 mulheres e 15 homens) na área de Antropologia, 26 (20 mulheres e 6 homens) na área de Sociologia, 13 (4 mulheres e 9 homens) na área de Direito, 13 na área de Serviço Social (9 mulheres e 4 homens), 12 (7 mulheres e 5 homens) na área de História e 4 (1 mulher e 3 homens) na área de Psicologia. 


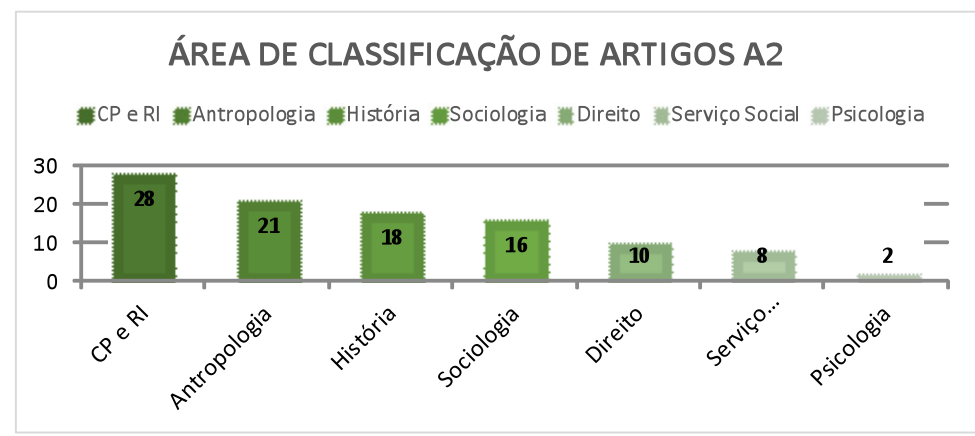

Figura 13 - Área de classificação de artigos A2 Fonte: Pesquisa de campo dos autores.

Ainda, foram pesquisados 62 artigos publicados em periódicos A1, sendo 25 na área de classificação de Ciência Política e Relações Internacionais, 18 em Direito, 8 em História, 4 em Sociologia, 3 em Psicologia, 73 em Serviço Social e 1 em Antropologia.

Saliente-se que foram contabilizados 108 autores e coautores (53 mulheres e 55 homens) destes artigos publicados em periódicos A1, sendo 42 (16 mulheres e 26 homens) na área de Ciência Política e Relações Internacionais, 28 (19 mulheres e 9 homens) na área de Direito, 11 (79 mulheres e 2 homens) na área de Psicologia, 11 na área de Serviço Social (5 mulheres e 6 homens), 10 (4 mulheres e 6 homens) na área de História, 4 (4 mulheres) na área de Sociologia e 2 (1 mulher e 1 homem) na área de Antropologia. 


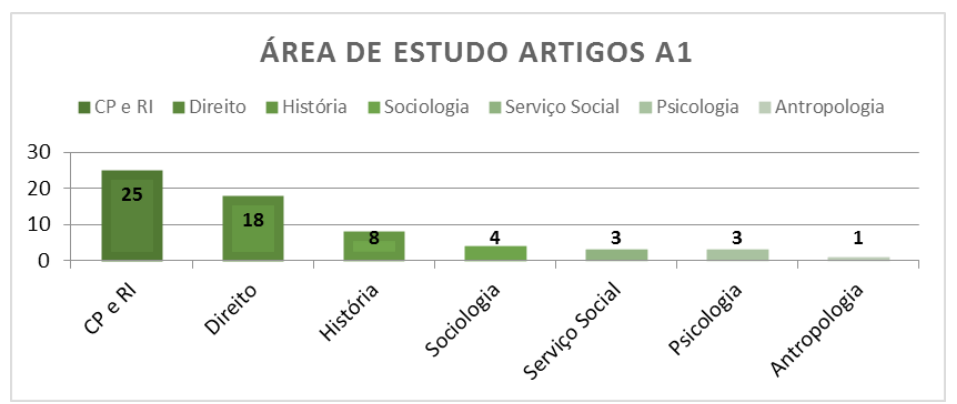

Figura 14 - Área de estudos de artigos A1 Fonte: Pesquisa de campo dos autores.

Quanto ao ano de publicação dos 340 artigos publicados nos periódicos A1, A2 e B1, entre 2007 e 2017, foram: 48 em 2017, 40 em 2014, 37 em 2016, 33 em 2015, 34 em 2013, 32 em 2011, 31 em 2008, 24 em 2009, 22 em 2012, 20 em 2010 e 19 em 2007.

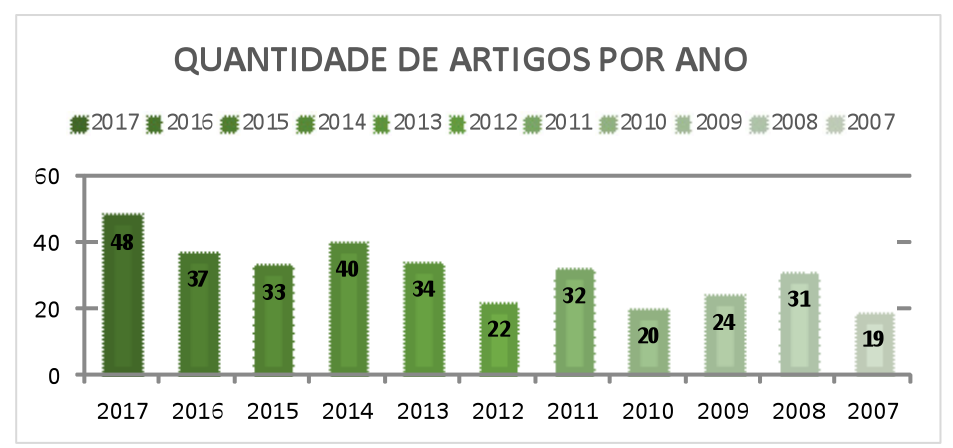

Figura 15 - Quantidade de artigos por ano

Fonte: Pesquisa de campo dos autores.

Depois da coleta de dados acima descrita, foi realizada nova análise dos dados coletados, conforme segue. Sobre teses e dissertações, foi possível classificá-las por categorias de pesquisa, da seguinte forma: 10 teses e 15 dissertações sobre migração, 
mobilidade ou deslocamento; 14 teses e 24 dissertações sobre refugiados; 1 tese e 2 dissertações sobre deslocados ambientais; 1 dissertação sobre traficados e 1 sobre apátridas; e nenhuma sobre deslocados internos.

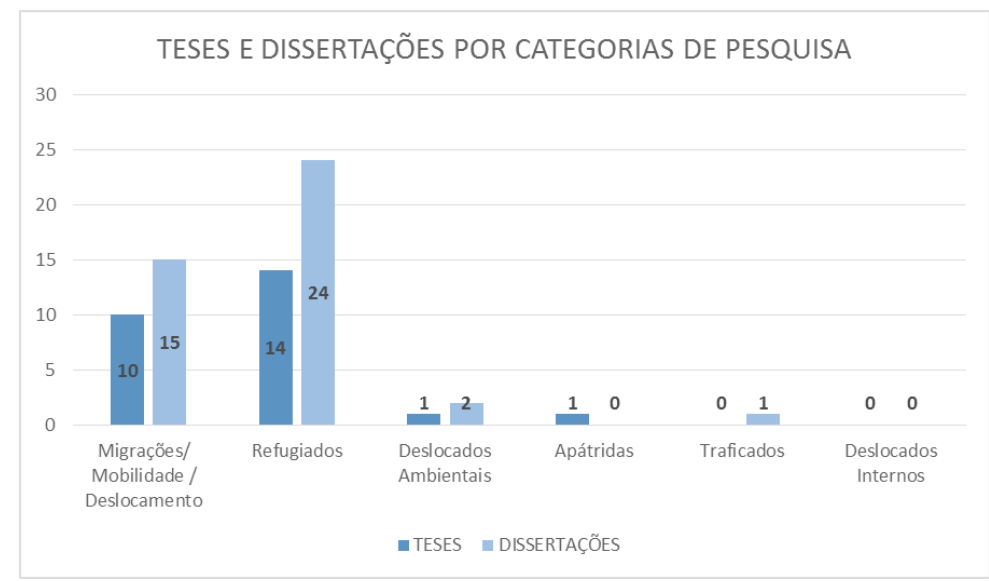

Figura 16 - Teses e dissertações por categorias de pesquisa

Fonte: Pesquisa de campo dos autores.

Foram analisados os temas mais recorrentes pesquisados nas teses e dissertações, cujos resultados foram os que seguem: 17 teses e 16 dissertações sobre Direito, lei e normas; 1 tese e 10 dissertações sobre proteção e assistência; 5 teses e 3 dissertações sobre hospitalidade, integração e gênero; 1 tese e 2 dissertações sobre crise; apenas uma tese sobre soluções; 6 teses e 8 dissertações sobre medidas e políticas públicas; 1 tese sobre história e narrativa; 3 teses e 4 dissertações sobre cultura; 1 tese e 2 dissertações sobre economia e trabalho; e 2 dissertações sobre saúde. 


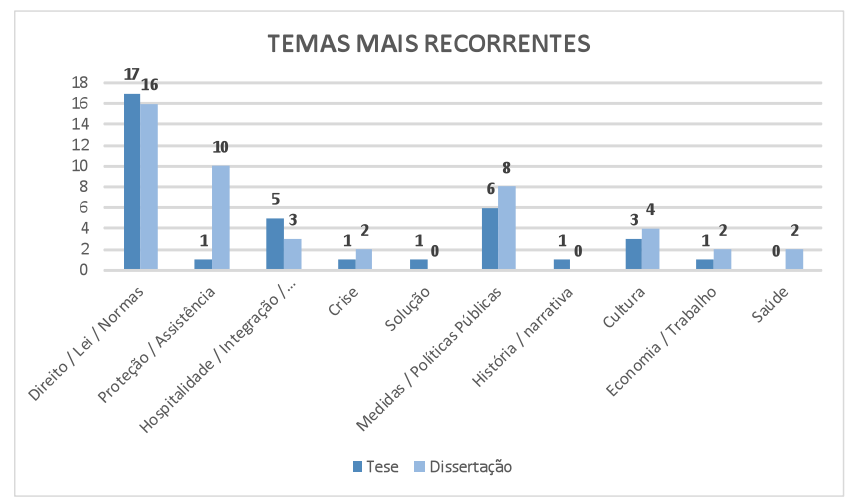

Figura 17-Temas mais recorrentes

Fonte: Pesquisa de campo dos autores.

Quanto às dimensões espaciais, foco de pesquisa das teses e dissertações, houve 12 teses e 19 dissertações com foco no sistema mundial; 1 dissertação sobre América Latina; 1 tese e 1 dissertação sobre União Europeia; 3 dissertações sobre África; 1 tese e 2 dissertações sobre Ásia; 4 teses e 2 dissertações com foco no Brasil; 4 teses e 3 dissertações sobre Haiti; 1 tese e 1 dissertação com foco em EUA e Canadá. Saliente-se que não houve nenhuma tese ou dissertação com foco na Síria.

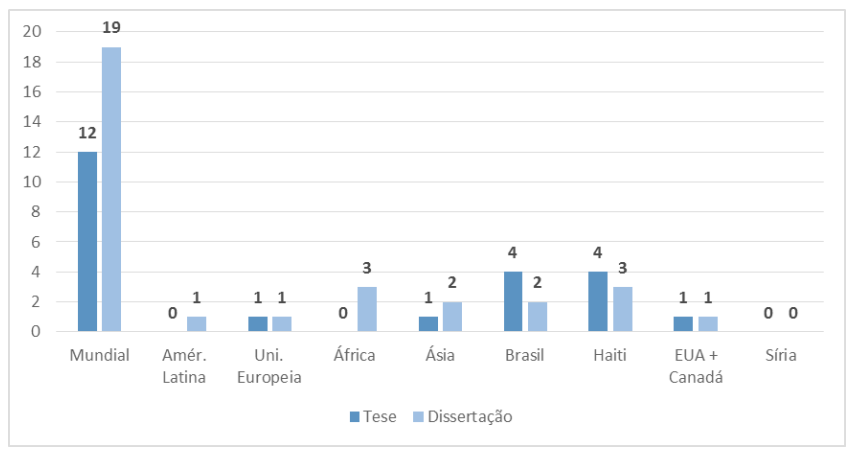

Figura 18 - Localização geográfica da pesquisa Fonte: Pesquisa de campo dos autores. 
Em seguida, analisando os dados coletados, foi possível classificar, por categorias de pesquisa, os artigos publicados em periódicos A1, A2 e B1 da seguinte forma:

- Sobre migração, mobilidade ou deslocamento, houve 139 artigos em periódicos B1; 61 artigos em periódicos A2; e 38 artigos em periódico A1.

- Sobre refugiados, houve 17 em B1; 11 em A2; e 9 em A1.

- Sobre deslocados internos, houve 4 em B1; e 1 em A2.

- Sobre deslocados ambientais, houve 8 em B1; 2 em A2; e 3 em A1.

- Sobre apátridas, houve 1 artigo para cada tipo de periódico (B1, A2 e A1).

- Sobre traficados, houve 16 em B1; 12 em A2, e 1 em A1.

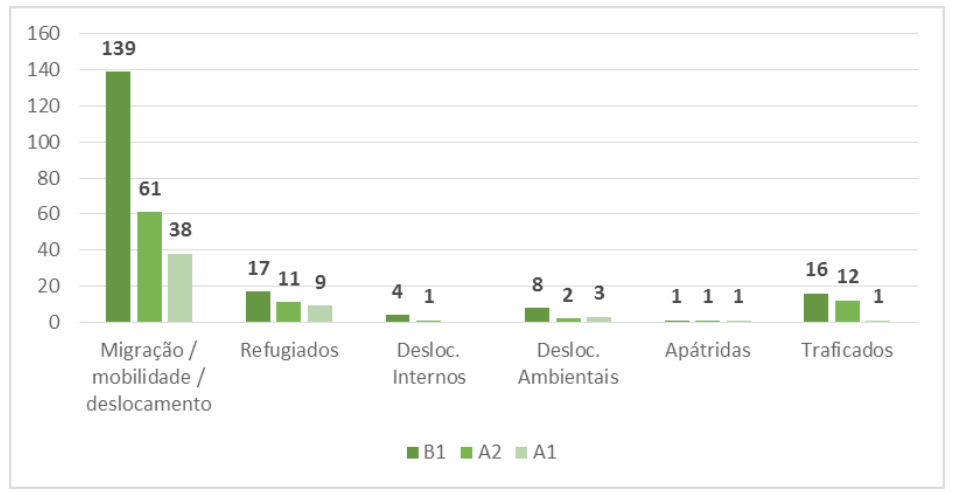

Figura 19-Categorias de pesquisa dos artigos publicados

Fonte: Pesquisa de campo dos autores.

Foram analisados os temas mais recorrentes dos artigos publicados nos periódicos A1, A2 e B1, cujo resultado foi o que segue: sobre direito, lei e normas, houve 45 artigos em B1, 18 em A2 e 10 em A1; sobre proteção e assistência, houve 21 
em B1, 18 em A2 e 3 em A1; sobre hospitalidade e integração, houve 13 em B1, 14 em A2 e 12 em A1; sobre crise, houve 4 em B1 e em A2; sobre soluções, houve 1 em B1, 1 em A2 e 2 em A1; sobre medidas e políticas públicas, houve 33 em B1, 10 em A2 e 6 em A1; sobre história e narrativa, houve 82 em B1, 8 em A2 e 2 em A1; sobre cultura, houve 4 em B1 e 3 em A2, sobre economia e trabalho, houve 9 em B1, 14 em A2 e 4 em A1; e, por fim, sobre saúde, houve 6 em B1, 5 em A2 e 10 em A1.

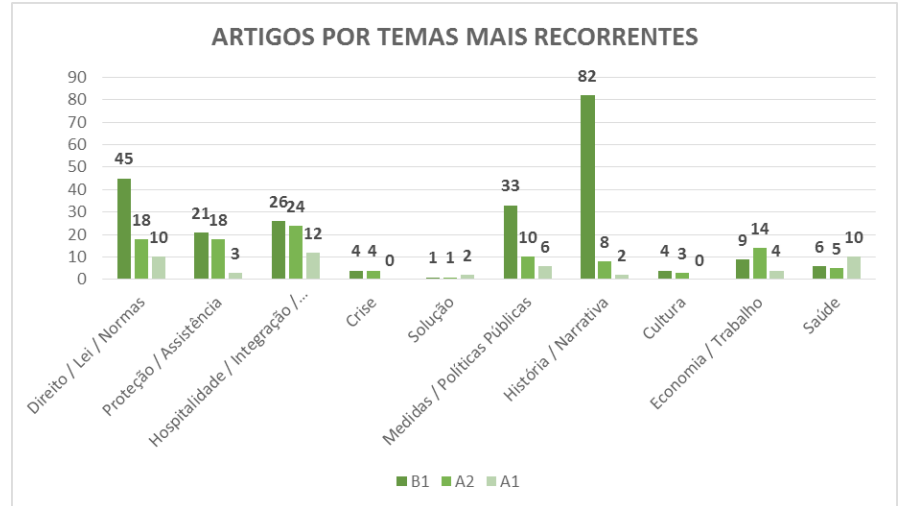

Figura 20 - Artigos por temas mais recorrentes Fonte: Pesquisa de campo dos autores.

Quanto às dimensões espaciais focos de pesquisa dos artigos publicados em A1, A2 e B1, o resultado foi o que segue:

- Com foco no sistema mundial, houve 66 artigos em B1; 37 em A2; e 27 em A1.

- Com foco na América Latina, houve 34 artigos em B1;11 em A2; e 3 em A1.

- Com foco na África, houve 6 artigos em B1; e 1 artigo para os tipos A2 e A1. 
- Com foco na União Europeia, houve 28 artigos em B1; 14 em A2; e 8 em A1.

- Com foco na Ásia, houve 2 artigos em B1; 3 em A2; e 4 em A1.

- Com foco nos EUA e Canadá, houve 8 artigos B1; 2 em A2; e 1 em A1.

- Com foco no Brasil, houve 50 artigos em B1, 16 em A2 e 4 em A1.

- Com foco no Haiti, houve 6 artigos em B1; 5 em A2,; e 3 em A1.

- Com foco na Síria, houve apenas 2 artigos em B1.

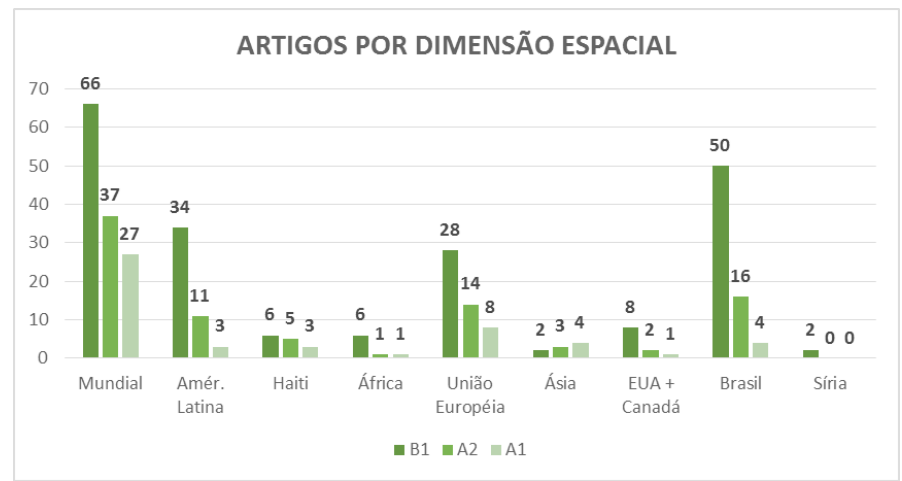

Figura 21 - Artigos por dimensão espacial

Fonte: Pesquisa de campo dos autores.

A pesquisa ainda buscou conhecer a origem/sede dos periódicos que publicaram os artigos, tendo encontrado os seguintes resultados: 61 periódicos $\mathrm{B} 1,44$ periódicos $\mathrm{A} 2$ e 34 periódicos A1, com sede nas seguintes localidades: 


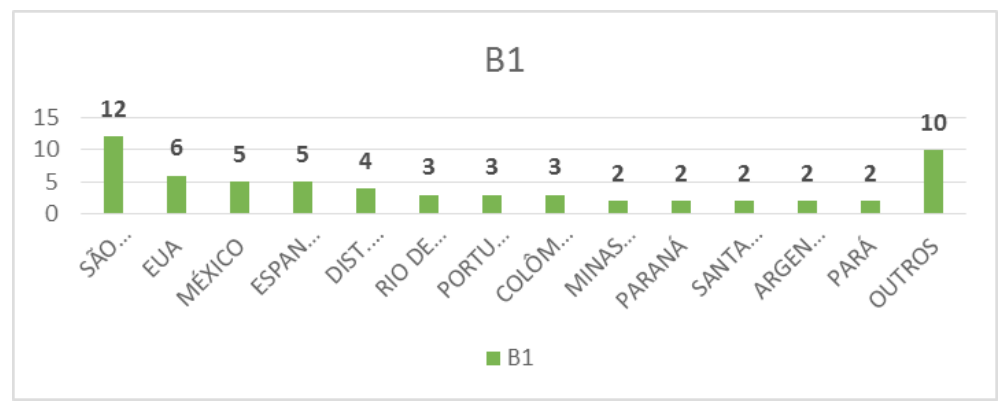

Figura 22 - Origem geográfica dos periódicos Fonte: Pesquisa de campo dos autores.

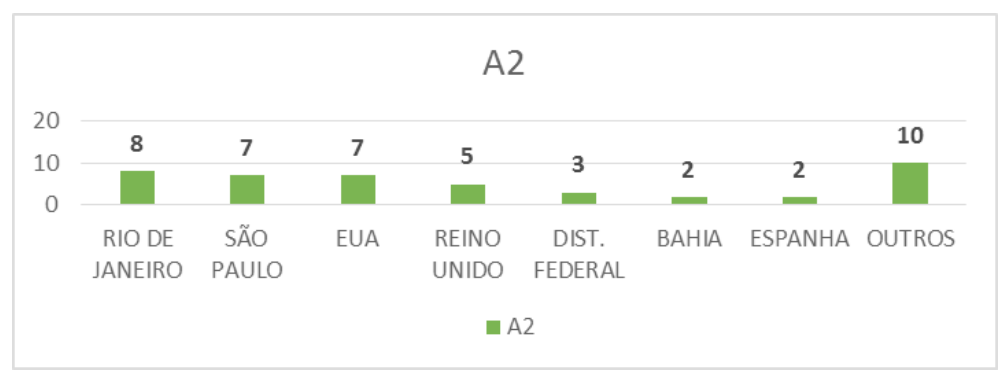

Figura 23 - Publicacações dos artigos em periódicos classificados como A2 Fonte: Pesquisa de campo dos autores.

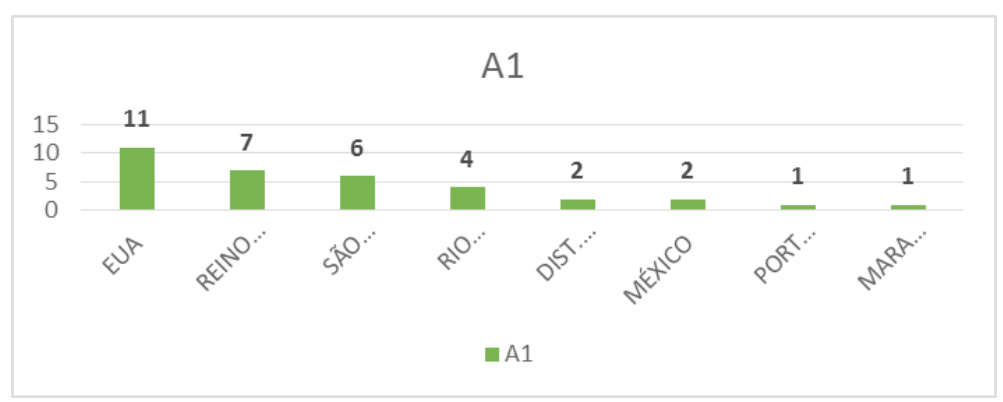

Figura 24 - Publicacações dos artigos em periódicos classificados como A1 Fonte: Pesquisa de campo dos autores. 
Ainda, analisando os dados coletados, foi possível classificar, por categorias de pesquisa, os TCC defendidos/apresentados em IES de João Pessoa- PB, da seguinte forma: 33 TCC abordam migração, mobilidade ou deslocamento; 7 abordam refugiados; 2 abordam deslocados ambientais; e 2 abordam traficados.

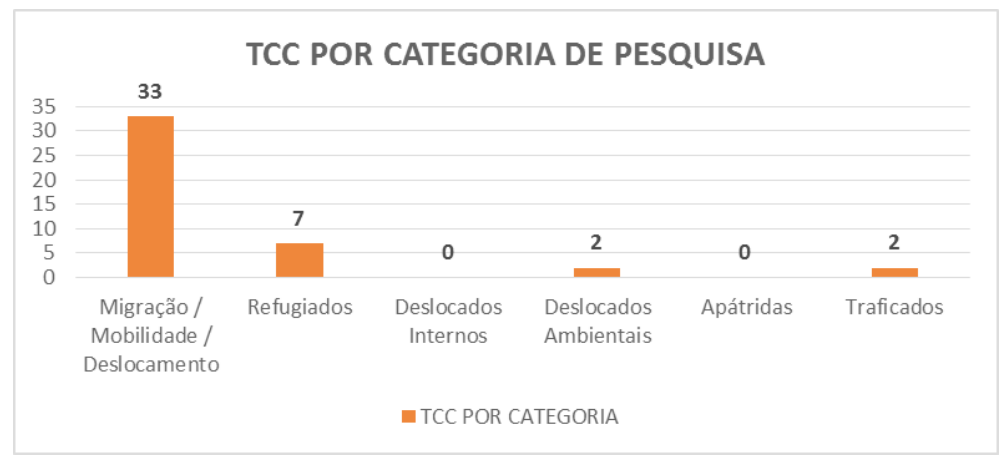

Figura 25 - TCC por categoria de pesquisa

Fonte: Pesquisa de campo dos autores.

Foram analisados os temas mais recorrentes dos TCC defendidos/apresentados em IES de João Pessoa/PB, cujo resultado foi o que segue: sobre direito, lei e normas, houve 26 TCC; sobre proteção e assistência, houve 15; sobre hospitalidade, integração e gênero, houve 4; sobre crise, houve 2; sobre soluções, houve 3; sobre medidas e políticas públicas, houve 5 trabalhos; e sobre cultura, houve apenas 1 TCC. Por fim, não houve TCC abordando os temas história/narrativa, economia/ trabalho e saúde. 


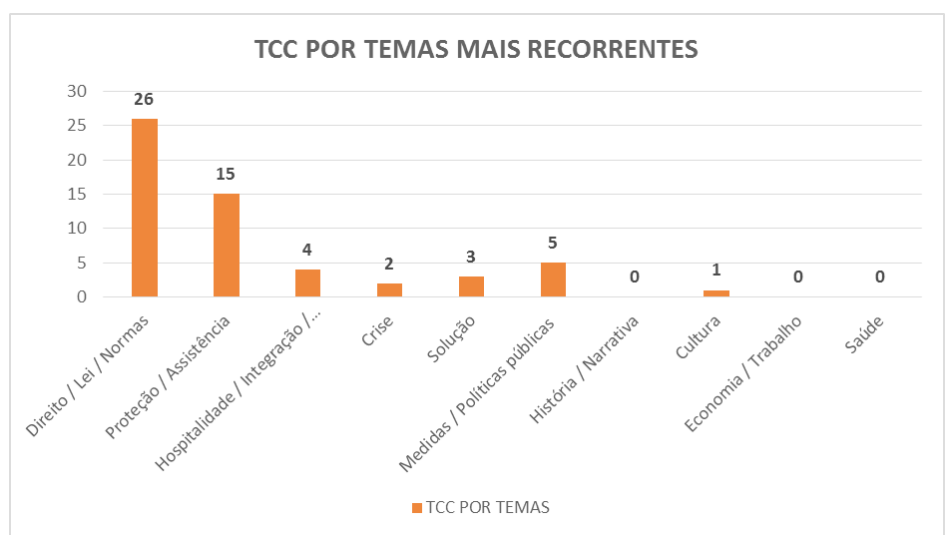

Figura 26-TCC por temas mais recorrentes Fonte: Pesquisa de campo dos autores.

Quanto às dimensões espaciais, foco de pesquisa dos TCC apresentados/defendidos, o resultado foi o que segue: 21 TCC abordaram o sistema mundial; 3 a América Latina; 4 a União Europeia; 1 a África; 4 a Ásia; 6 o Brasil; 2 o Haiti; e 1 EUA/ Canadá.

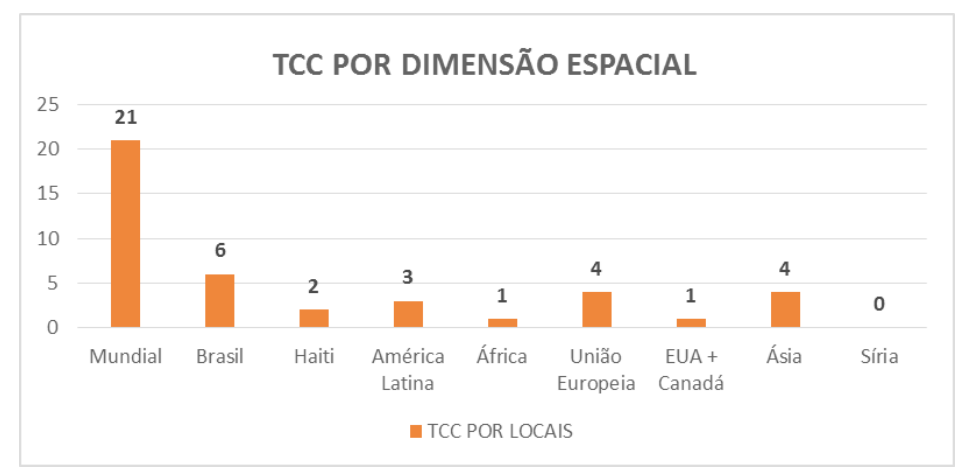

Figura 27-TCC por dimensão espacial

Fonte: Pesquisa de campo dos autores. 